\title{
A Fracture-Based Criterion for Debonding Strength of Adhesive-Bonded Double-Strap Steel Joints
}

\author{
Akhrawat Lenwari ${ }^{*}$, Thaksin Thepchatri, and Prawit Santisukpotha \\ Department of Civil Engineering, Faculty of Engineering, Chulalongkorn University, Phayathai Rd., \\ Pathumwan, Bangkok 10330, Thailand \\ E-mail: akhrawat.1@chula.ac.th*
}

\begin{abstract}
This paper addresses the debonding strength of adhesive-bonded doublestrap steel joints. A fracture-based criterion was formulated in terms of a stress singularity parameter, i.e., the stress intensity factor, which governs the magnitude of a singular stress field near the joint ends. No existing crack was assumed. A total of 24 steel joint specimens were tested under constant amplitude fatigue loadings at stress ratio of 0.2 and frequency of $2 \mathrm{~Hz}$. The joint stiffness ratio was slightly less than one to control the maximum adhesive stresses at the joint ends. To detect the debonding, a simple and practical technique was developed. The test results showed that the interfacial failure near the steel/adhesive corner was a dominant failure mode. The failure was brittle and the debonding life was governed by the crack initiation stage. The finite element analysis was employed to calculate the stress intensity factors and investigate the effects of the adhesive layer thickness, lap length and joint stiffness ratio on the debonding strength.
\end{abstract}

Keywords: Double-strap joints, adhesive bonding, fatigue, debond detection, bimaterial, Reciprocal work contour integral, stress singularity.

ENGINEERING JOURNAL Volume 16 Issue 1

Received 20 June 2011

Accepted 9 September 2011

Published 1 January 2012

Online at http://www.engj.org

DOI:10.4186/ej.2012.16.1.17 


\section{Introduction}

An adhesive bonding has been widely used to connect both metallic and non-metallic structural members. Dissimilar materials such as steel, concrete, fiber-reinforced polymers (FRP) can be joined. For bridge structures subjected to repetitive loadings, an adhesive bonding offers good fatigue performance in that cracking is not likely to occur in load-carrying members. Albrecht et al. [1] reported that the bonded and bolted connections exhibit much higher fatigue strength than typical welded connections. However, one main disadvantage of an adhesive bonding is that a very high local stress field can lead to a debonding failure which governs the static and fatigue strengths of the bonded joints.

In comparison with the stress-based approach, the fracture-based approach has been less employed to assess the strength of adhesive-bonded joints [2-14]. Typically, cracks are assumed to exist in adhesive-bonded joints. The fracture mechanics is then applied to predict the failure load at the instance when the stress intensity factor, which is the magnitude of the singular stress field near the singular point (i.e. crack tip), reaches the critical value. The singularity criterion is particularly suitable for structures subjected to a fatigue loading conditions in which a small-scale yielding can be assumed. From the linear elasticity viewpoint, however, the stress singularity also exists near the corner of a bimaterial wedge [15-17], as shown in Fig. 1, which is the condition at the joint ends.

This paper presents a fracture-based criterion for the debonding strength of adhesive-bonded steel joints subjected to constant amplitude fatigue loadings. The double-strap joint configuration, which was commonly used in practice and recommended in many standard test methods, was chosen. The Reciprocal Work Contour Integral Method (RWCIM) was used to calculate a stress intensity factor, the singularity parameter which governs the singular stress field. No preexisting crack was assumed. Finally, the effects of joint parameters on the stress intensity factors were discussed using the finite element analysis results.

\section{Reciprocal Work Contour Integral Method (RWCIM)}

Figure 1 shows an elastic bi-material wedge which is the condition at the joint end. The stress field near the wedge corner, a singular point, can be expressed as

$$
\sigma_{i j}(r, \theta)=\sum_{k=1}^{N} \frac{K}{r^{\alpha_{k}}} f_{i j k}(\theta)+\sigma_{i j o}(\theta)
$$

where $r$ and $\theta=$ polar coordinates; $N=$ number of $r$-dependent stress terms; and $f_{i j k}(\theta)$ is a function dependent on the angle $\theta$. The regular term, $\sigma_{i j o}(\theta)$, and the constant $K$ depend on the loading and global geometry. The strengths of singularity, $\alpha_{k}$, depend on the elastic moduli ( $E_{1}, E_{2}$ ), the Poisson's ratio $\left(v_{1}, v_{2}\right)$, and the angle $\theta_{1}$ and $\theta_{2}$ of the bi-material [15].

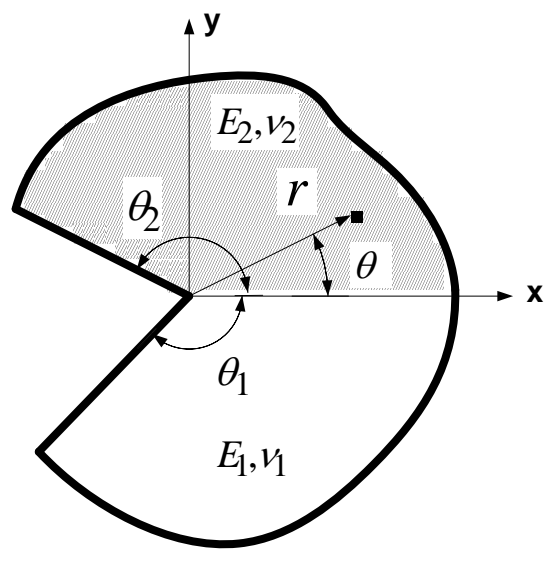

( a )

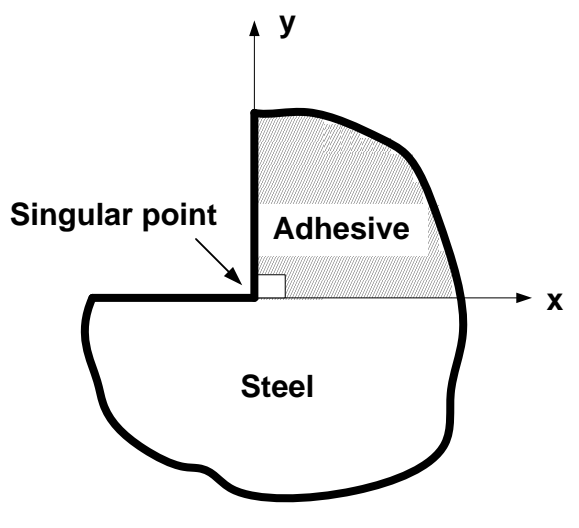

(b)

Fig. 1. Bi-material wedge (a) general (b) this study (square end). 
When only the strongest singularity (dominant singularity), $\alpha_{1}$, is considered, the stress field near the singular point along a specific angle can be written as

$$
\sigma_{i j}(r, \theta)=Q_{i j} / r^{\alpha_{1}}
$$

In this study, the values of $Q_{i j}$, defined as the stress intensity factor, in MPa-mm ${ }^{\alpha_{1}}$, are calculated using the RWCIM [18-19]. The advantage of the method is that the finite element solutions including stresses and displacements are only used in the region away from the singular point where a relatively coarse mesh is sufficient. Therefore, the very fine finite element mesh or a special element near the singular point is not required.

\section{Experimental Program}

\subsection{Specimen design}

Figure 2 shows a double-strap steel joint used as a test specimen. Based on the shear lag analysis [20], the joint was designed to have the value of stiffness ratio, i.e., the ratio of the axial stiffness of the inner adherend to the sum of axial stiffnesses of the two outer adherends, equal to 0.96 which is slightly less than one. This results in the maximum adhesive stresses at the joint ends. This joint design also represents a typical steel joint design which prevents the failure of the outer adherends.

In the experiments, the properties of the steel/adhesive bi-material were $E_{1}=200 \mathrm{Gap}, v_{1}=0.3$, $E_{2}=2.75 \mathrm{Gap}$, and $v_{2}=0.35$. The adhesive angle was perpendicular to the bottom flange (square end condition) with $\theta_{1}=180^{\circ}$ and $\theta_{2}=90^{\circ}$. Singular points are corners A, B, C, and D. In a study by Lennar [21], the dominant singularities at corner $\mathrm{A}$ and $\mathrm{D}$ were found to be 0.271 and 0.326 under plane stress and plane strain, respectively, while those at corner B and C were 0.248 and 0.305 under plane stress and plane strain, respectively. In the experiments, a spew fillet can occur at the corner D which leads to a reduction of singularity.

The grade of steel plates was SS400 according to TIS 1227 (equivalent to JIS G3101). The steel surface was sandblasted according to the Steel Structure Painting Council specification no. 5 [22] and cleaned with an isopropyl alcohol before the adhesive was applied. The adhesive used was Sikadur ${ }^{\circledR 30}$, a two-part epoxy. The thickness of an adhesive layer was controlled to be $1 \mathrm{~mm}$. The condition at the joint terminus was square end. The curing time for adhesive was at least 2 weeks before testing.
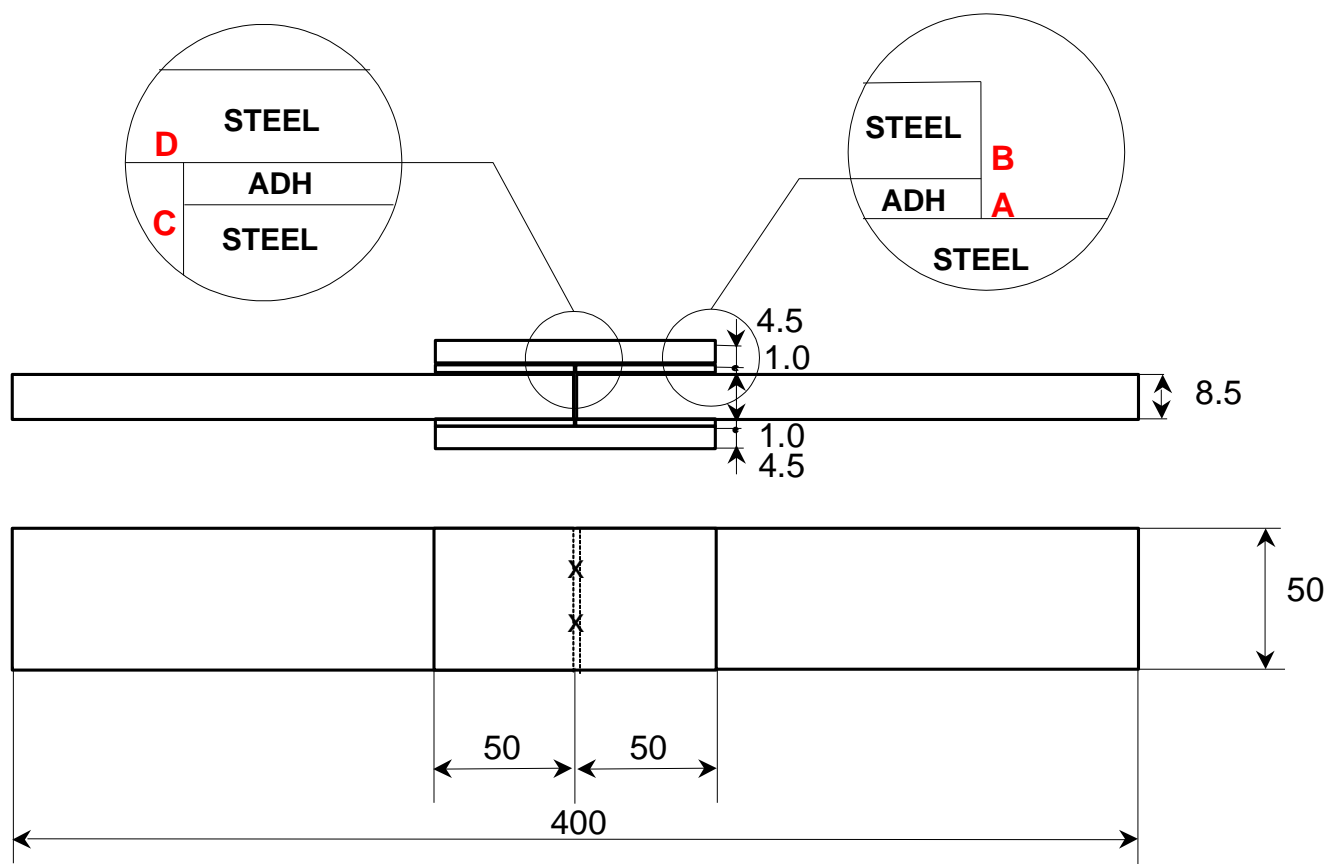

Fig. 2. Double-strap steel joint specimen (dimensions in millimeter). 


\subsection{Constant amplitude fatigue tests}

A total of 24 specimens were tested under constant amplitude fatigue loadings. Sine-waveform loadings were generated by a servo-hydraulic actuator. The stress ratio (R), i.e., the minimum-to-maximum stress ratio, was 0.2 and the test frequency was $2 \mathrm{~Hz}$. All tests were performed at an ambient temperature.

Seven levels of stress ranges having maximum stresses correspond to $17 \%, 40 \%, 50 \%, 60 \%, 65 \%$, $70 \%$, and $80 \%$ of the joint static strength were investigated. Based on a static test on three joints which revealed the strengths of $84.9,95.2$, and $83.4 \mathrm{ken}$, the lowest value $(83.4 \mathrm{ken})$ was used as the joint static strength.

A simple technique was developed to automatically detect the joint debonding. A sensor with a silver line tracing across the adhesive terminus was constructed at the joint end, as shown in Fig. 3. As the joint debonded, the silver trace was cut, causing the measured voltage to a zero value. In this technique, it was necessary to prevent the current flow by spraying a thin layer of an insulating material before tracing the silver line because steel material is electrically conductive. This technique was also employed in a study on the debonding strength of steel beams strengthened with CFRP plates [23].

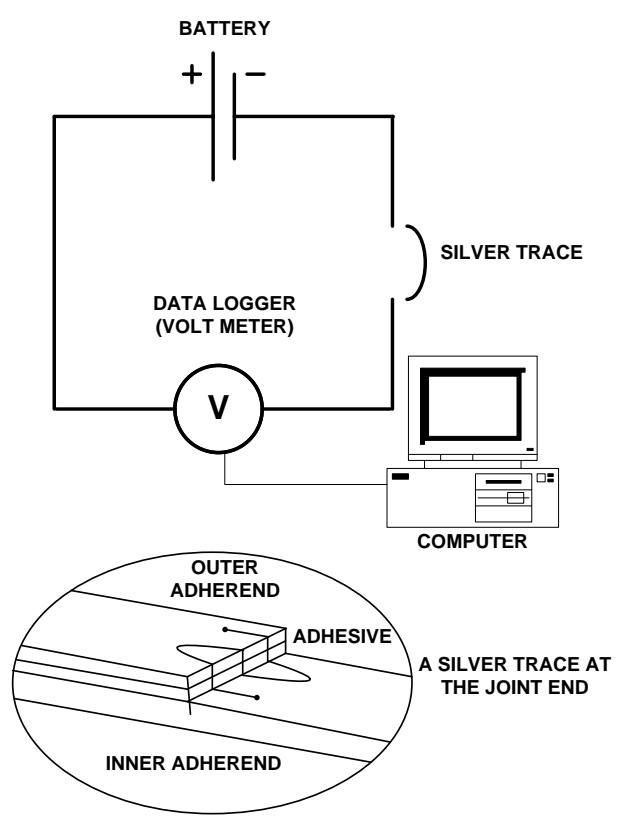

Fig. 3. Debond detection technique (schematic).

\section{Finite Element Modelling}

A 2D finite element model of the double-strap joint is shown in Fig. 4. A quarter model was analyzed due to symmetry. The elements used were 8-node elements having two degrees of freedom at each node. Lennar et al. [24] assumed a plane strain condition since the plate was rigid compared with the adhesive and, further, the joint thickness was small compared with the joint width. In this study, both plane stress and plane strain conditions were assumed. The mesh near the joint end is shown Fig. 5. Elements near a singular point had a length of $t_{a} / 8$, where $t_{a}$ is an adhesive layer thickness. Other elements have the size of approximately $1 \mathrm{~mm}$. The RWCIM was used to calculate the value of stress intensity factors at singular point A in Fig. 2. 


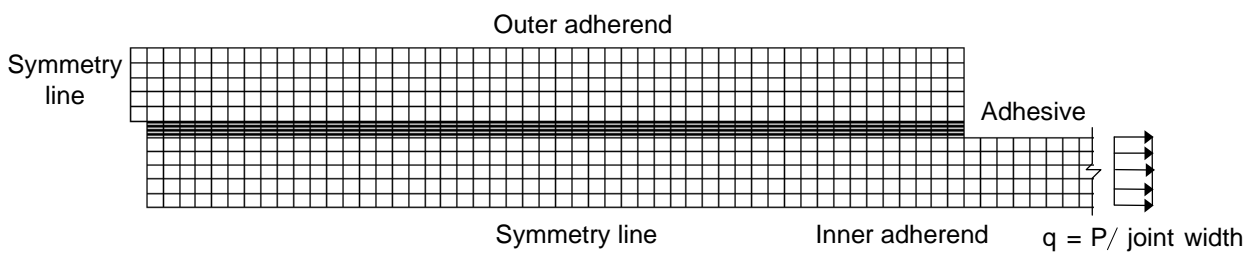

Fig. 4. Quarter model of double-strap joint.

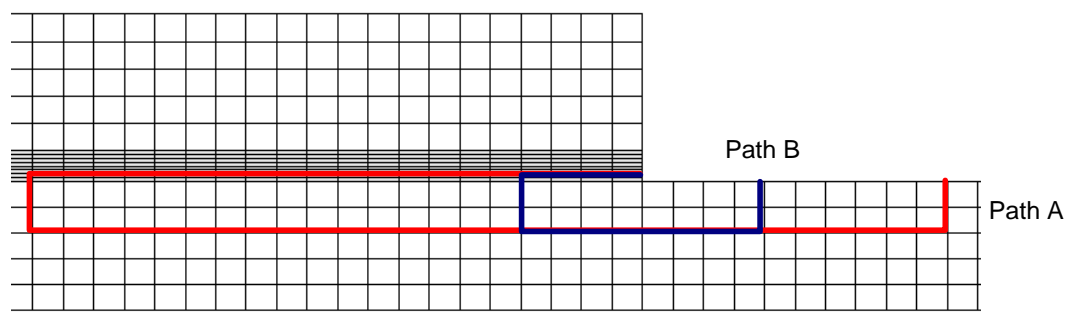

Fig. 5. Mesh near the joint terminus and contours.

In the RWCIM, the finite element solutions were used along the outer contour. The chosen contours were rectangles, namely, path A and B (as shown in Fig. 5). Along the inner contour the singular solution was used. The chosen inner contour was a circular segment with a radius of $0.001 \mathrm{~mm}$ [21]. The numerical integration along the contour was carried out by the trapezoidal rule. A convergent study was conducted to ensure a sufficient number along contour points and mesh fineness.

\section{Results and Discussion}

\subsection{Debonding strength and failure mode}

Figure 6 shows a measured voltage signal from the sensor during the fatigue testing. Typically, all joints failed suddenly once visible cracks occurred, thus causing an abrupt change to zero voltage in all specimens. The moment when the voltage value became zero was used to determine the debonding life.

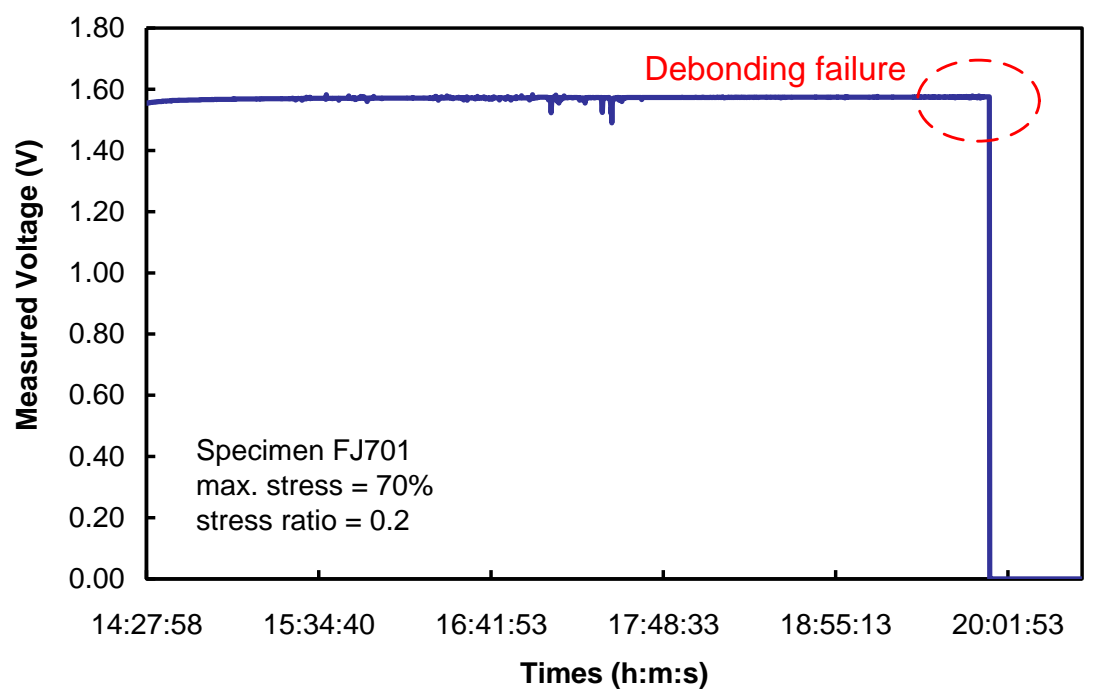

Fig. 6. Example voltage signal from a sensor.

Figure 7 shows an interfacial failure along the steel/adhesive corners at the joint ends, which is typical for the joints. A surface preparation before bonding process significantly influences the 
interfacial failures. One advantage of adhesive bonding was that no fatigue crack initiated at the steel plates.

Figure 8 plots the relationships between the stress intensity factor range and the cycles to debonding. The data with arrows indicate that the joint did not fail when the test stopped at 1.5 million cycles. The debonding strength criterion obtained from regression analysis of experimental data was proposed

$$
\begin{array}{lll}
\Delta Q_{\theta \theta}=-1.5367 \operatorname{Ln}(N)+29.226 & \text { under plane strain condition } \\
\text { and } & \Delta Q_{\theta \theta}=-1.8573 \operatorname{Ln}(N)+35.324 & \text { under plane stress condition }
\end{array}
$$

where $\Delta Q_{\theta \theta}=$ ranges of stress intensity factor along the interface in $\mathrm{MPa}-\mathrm{mm}^{0.271}$ and $\mathrm{MPa}-\mathrm{mm}^{0.326}$ for plane stress and plane strain conditions, respectively; and $N=$ number of cycles to debonding. The coefficient of determination in Eq. (3) and (4) is $r^{2}=0.88$. Because the values of ratio $Q_{r r} / Q_{r \theta}$ were 1.34 and 1.70 for plane stress and plane strain conditions, respectively, and the ratio $Q_{\theta \theta} / Q_{r \theta}$ were 3.65 and 3.24 for plane stress and plane strain conditions, respectively, any stress intensity factor, $Q_{i j}$, can be used as the debonding strength criterion. The test data also suggested that an endurance limit might exist, under which the joint has no chance of debonding.

A similar criterion can be constructed for other bi-material's properties, i.e., steel substrate and adhesive layer, and interface characteristics, i.e., surface treatment, for evaluating the debonding failure in real structures.

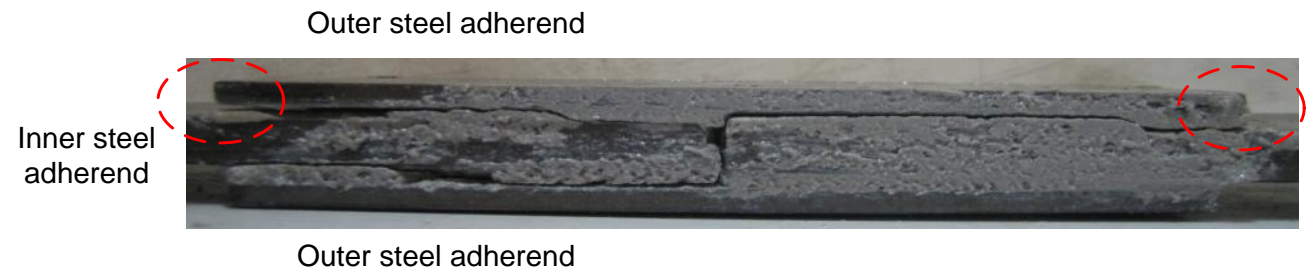

Fig. 7. Debonding failure of specimens.

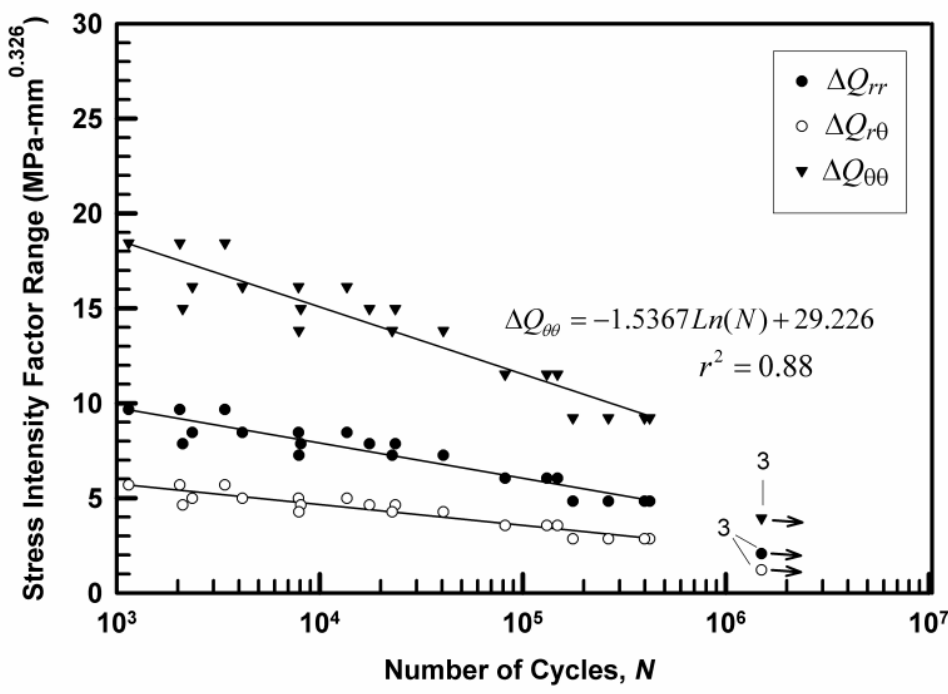

Fig. 8. Fracture-based criterion for debonding strength (plane strain condition).

\subsection{Effects of adhesive layer thickness, joint stiffness ratio and lap length}

A finite element analysis was performed to investigate the effects of joint parameters including the joint stiffness ratio, adhesive layer thickness, and lap length on the stress intensity factors. A case study was the joint subjected to an axial force of $86.8 \mathrm{kN}$. The stress intensity factors were calculated from RWCIM under plane strain condition. The properties of the joint, except the value of the parameter in the investigation, were same as those of the joint specimen. 
Figure 9 shows the effect of lap length on stress intensity factors $Q_{r r}, Q_{r \theta}, Q_{\theta \theta}$ along the interface. The lap length was varied at $25,50,100$, and $250 \mathrm{~mm}$. The values of stress intensity factors decrease as the lap length increases. This implies that the joint with longer lap length has a longer life when subjected to the same fatigue loading. Beyond a specific lap length, however, the debonding strength is practically insensitive to the lap length. This observation is in agreement with the stress-based criterion which predicts no increase in elastic static strength when the lap length is beyond a particular limit [25].

Figure 10 shows the effect of joint stiffness ratio on stress intensity factors $Q_{r r}, Q_{r \theta}, Q_{\theta \theta}$ along the interface. The stiffness ratio was varied at $0.2,0.5,0.94$, and 2 . The values of stress intensity factors decrease as the stiffness ratio increases. This implies an increase in the debonding strength as the sum thickness of outer adherends decreases, while the thickness of the inner adherend is kept constant. However, the static strength of joint will be governed by the yielding failure of the outer adherend. Moreover, the debonding failure can occur at other singular points, e.g., singular point D in Fig. 2, when the stiffness ratio is greater than one. This is because the location of maximum adhesive stresses is not at the joint end [25]. Therefore, an unbalance joint with a stiffness ratio value slightly less than one is recommended.

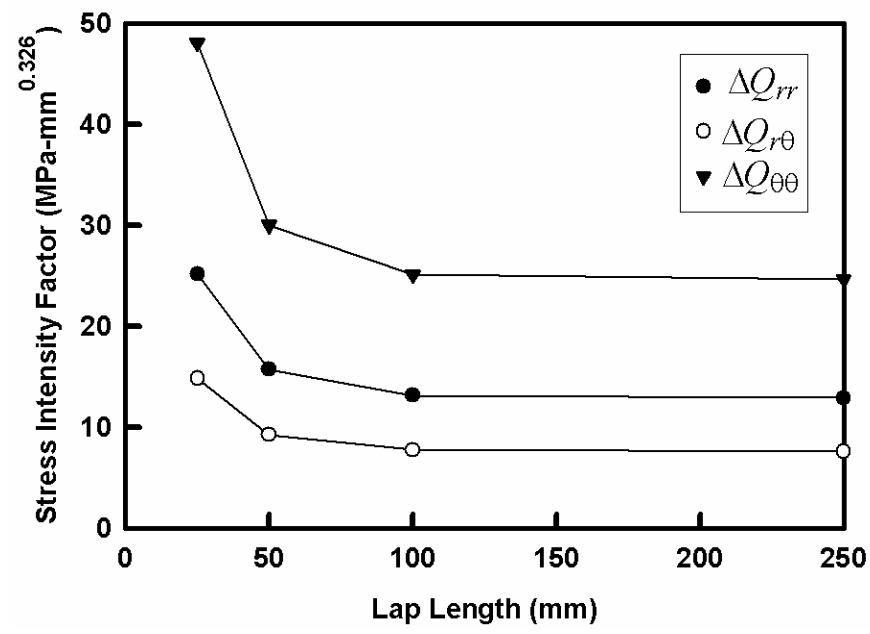

Fig. 9. Effect of lap length on stress intensity factors.

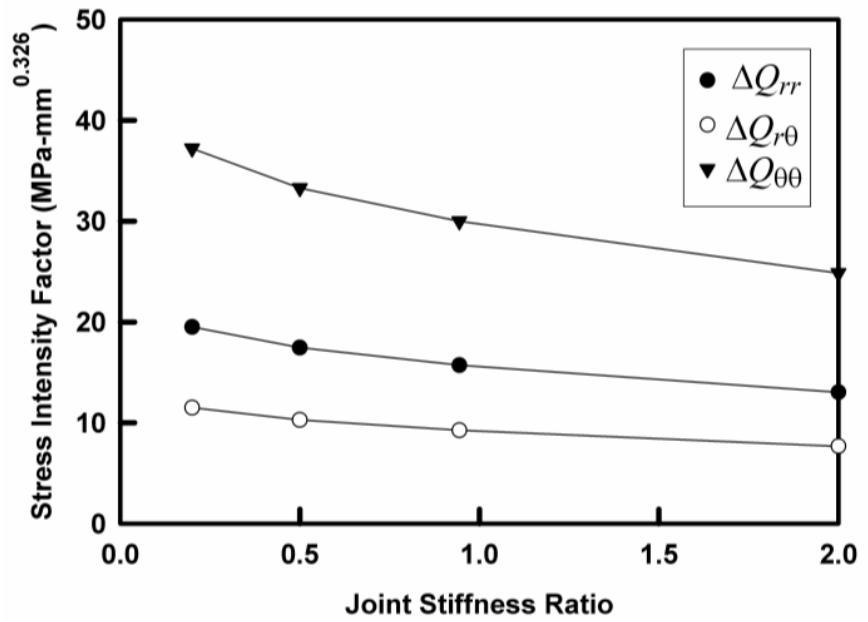

Fig. 10. Effect of joint stiffness ratio on stress intensity factors.

Figure 11 shows the effect of adhesive layer thickness on the stress intensity factors $Q_{r r}, Q_{r \theta}, Q_{\theta \theta}$ along the interface. The adhesive layer thickness was varied at $0.5,1,2$, and $5 \mathrm{~mm}$. The stress intensity factors increase with the adhesive layer thickness. However, the effect of adhesive layer thickness is less pronounced than those of the lap length and joint stiffness ratio. 
From the results, the lap length was found to be the most affecting factor on the stress intensity factors provided that the interfacial failure near the steel/adhesive corner was a governing failure mode. Similar results were found in case of plane stress condition.

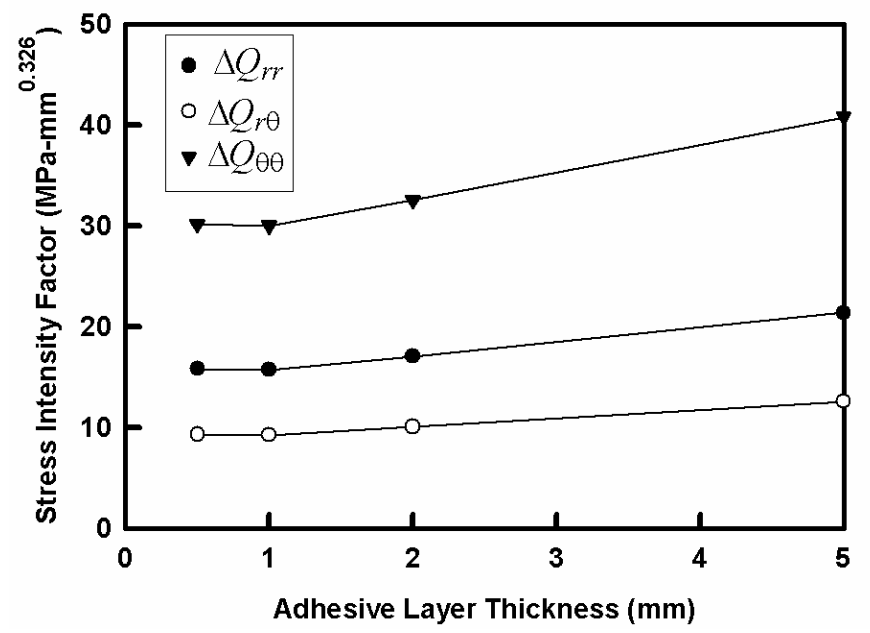

Fig. 11. Effect of adhesive layer thickness on stress intensity factors.

\section{Conclusions}

This study extends the elastic fracture criterion for typical crack problems to investigate the debonding strength of adhesive-bonded double-strap joints subjected to constant-amplitude fatigue loadings. No preexisting crack was assumed. The singularity is based on the bi-material wedge condition at the joint ends. The main conclusions from both experiments and analyses can be summarized as follows:

1. Adhesive (interfacial) failure was observed near the steel/adhesive corners. Therefore, the surface preparation significantly affects the joint debonding strength.

2. The debonding life was governed by the crack initiation. All joints failed suddenly once visible cracks occurred.

3. A debonding strength criterion was proposed in terms of a stress intensity factor. The criterion is limited to the same bi-material properties, i.e., same value of strength of singularity, and interface characteristics.

4. Based on the finite element analysis, the debonding strength increases with the lap length and joint stiffness ratio but decreases as the adhesive layer becomes thicker.

5. The lap length is the most affecting factor on the debonding strength provided that the interfacial failure near the steel/adhesive corner at the joint end was a governing failure mode.

\section{Acknowledgements}

The authors would like to acknowledge the grant for development of new faculty staff and the Ratchadapiseksomphot Endowment Fund (CU-CLUSTER-Advanced-7-57-53) from Chulalongkorn University. Thanks to Sika Thailand, Ltd. for providing adhesive materials and the assistance on specimen preparation. The financial support from Chulalongkorn graduate school thesis grant to the third author is also appreciated.

\section{References}

[1] P. Albrecht, A. Sahli, D. Crute, Ph. Albrecht, and B. Evans, "Application of adhesives to steel bridges." Final Report, FHWA/RD-84/037, Federal Highway Administration, McLean, Virginia, 1984. 
[2] H. L. Groth, "A method to predict fracture in an adhesively bonded joint," Int. J. Adhes. Adhes., vol. 5, no. 1, pp. 19-22, 1985.

[3] A. J. Kinloch, Adhesion and Adhesive: Science and Technology. London: Chapman \& Hall, 1987.

[4] T. Hattori, S. Sakata, T. Hatsuda, and G. Murakami, "A stress singularity parameter approach for evaluating adhesive strength,” JSME Int. J., Series I, vol. 31, no. 4, pp. 718-723, 1988.

[5] T. Hattori, "A stress-singularity-parameter approach for evaluating the adhesive strength of single-lap joints," JSME Int. J. Series I, vol. 34, no. 3, pp. 326-331, 1991.

[6] E. D. Reedy Jr. and T. R. Guess, "Comparison of butt tensile strength data with interface corner stress intensity factor prediction," Int. J. Solids Struct., vol. 30, no. 21, pp. 2929-2936, 1993.

[7] M. Imanaka and T. Iwata, "Effect of adhesive layer thickness on fatigue strength of adhesively bonded butt, scarf and butterfly type butt joints," Int. J. Fract., vol. 80, pp. R69-R76, 1996.

[8] M. Imanaka, K. Ishii, and H. Nakayama, "Evaluation of fatigue strength of adhesively bonded single and single step double lap joints based on stress singularity parameters," Eng. Fract. Mech., vol. 62, pp. 409-424, 1999.

[9] D. R. Lefebvre and D. A. Dillard, "A stress singularity approach for the prediction of fatigue crack initiation in adhesive bonds. part 1: theory," J. Adhes., vol. 70, pp. 119-138, 1999.

[10] D. R. Lefebvre and D. A. Dillard, "A stress singularity approach for the prediction of fatigue crack initiation in adhesive bonds. part 2: experimental," J. Adhes., vol. 70, pp. 139-154, 1999.

[11] M. Quaresimin and M. Ricotta, "Life prediction of bonded joints in composite materials," Int. J. Fatigue, vol. 28, pp. 1166-1176, 2006.

[12] M. Bocciarelli, P. Colombi, G. Fava, and C. Poggi, "Prediction of debonding strength of tensile steel/CFRP joints using fracture mechanics and stress based criteria," Eng. Fract. Mech., vol. 76, no. 2, pp. 299-313, 2009.

[13] S. Azari, M. Eskandarian, M. Papini, J. A. Schroeder, and J. K. Spelt, "Fracture load predictions and measurements for highly toughened epoxy adhesive joints," Eng. Fract. Mech., vol. 76, pp. 2039-2055, 2009.

[14] N. Choupani, "Characterization of fracture in adhesively bonded double-lap joints," Int. J. Adhes. Adhes., vol. 29, pp. 761-773, 2009.

[15] D. B. Bogy, "Two edge-bonded elastic wedges of different materials and wedge angles under surface tractions," J. Appl. Mech., vol. 35, pp. 377-386, 1971.

[16] V. L. Hein and F. Erdogan, "Stress singularities in a two-material wedge," Int. J. Fract., vol. 7, no. 3, pp. 317-330, 1971.

[17] J. P. Dempsey and G. B. Sinclair, "On the singular behavior at the vertex of a bi-material wedge," J. Elast., vol. 11, no. 3, pp. 317-327, 1981.

[18] W. C. Carpenter and C. Byers, "A path independent integral for computing stress intensities for V-notched cracks in a bi-material," Int. J. Fract., vol. 35, pp. 245-268, 1987.

[19] W. C. Carpenter, "Insensitivity of the reciprocal work contour integral method to higher order eigenvectors," Int. J. Fract., vol. 73, pp. 93-108, 1995.

[20] O. Volkersen, "Die Nietkraftverteilung in Zugbeanspruchten Nietverbindungen mit Konstanten Laschenquerschnitten," Luftfahrtforschung, vol. 15, pp. 41-47, 1938 (in German).

[21] A. Lennar, "Terminal distances for CFRP plates adhesively bonded to steel girders." Ph.D. thesis, Chulalongkorn University, Bangkok, Thailand, 2002.

[22] Society for Protective Coatings (SSPC). SSPC-SP 5/NACE No. 1, White Metal Blast Cleaning, SSPC, Pittsburgh, 2000.

[23] A. Lennar, T. Thepchatri, and P. Albrecht, "Debonding strength of steel beams strengthened with CFRP plates," J. Compos. Constr., ASCE, vol. 10, no. 1, pp. 69-78, 2006.

[24] A. Lennar, T. Thepchatri, and E. Watanabe, "Prediction of premature separation of bonded CFRP plates from strengthened steel beams using a fracture criterion," Struct. Eng. Mech., vol. 14 , no. 5, pp. 565-574, 2002.

[25] L. J. Harth-Smith. (1973). Adhesive-bonded double-lap joints. NASA Langley Report CR112235. [Online] Available HTTP: //ntrs.nasa.gov/archive/nasa/casi.ntrs.nasa.gov/ 19740005082_1974005082.pdf 
